\title{
ANALISIS FAKTOR-FAKTOR YANG BERHUBUNGAN DENGAN SIKAP MAHASISWA KEPERAWATAN SEMESTER V DAN VII TENTANG HUBUNGAN SEKSUAL (INTERCOURSE) PRANIKAH DI PROGRAM STUDI S1 KEPERAWATAN FAKULTAS ILMU KESEHATAN UNIVERSITAS WIRARAJA SUMENEP
}

Sri Sumarni, Program Studi IImu Keperawatan UNIJA Sumenep

e-mail: sri.sumarni73@yahoo.co.id

Iva Gamar Dian Pratiwi, Program Studi Kebidanan UNIJA Sumenep

e-mail: kura_15587@yahoo.com

\section{ABSTRACT}

Teenage association at this time has reached the stage of worrying. All the mass media both electronic and print media by displaying things that could lead to the destruction of morality of the young generation at this time. Teenagers in the past and present are very different and very irrelevant anymore.

Data from BKKBN mention that pregnancy rate among adolescent in Indonesia is high enough that 48 out of 1000 adolescents, and 58\% teenage girl who get pregnant outside of marriage have desire to have abortion.

General Purpose of This Research is To know the factors related to attitude of nursing students of semester $V$ and VII about premarital sexual intercourse at Nursing Study Program Faculty of Health Sciences.

This type of research is observational using Cross-Sectional approach. Population taken in this research is nursing student of semester VII at Health Faculty of University of Wiraraja Sumenep counted 128 student. Including male and female students, then simplified back with a slovin formula obtained 100 samples. Using total sampling sampling techniques. Data Analysis Method using Pearson Product Moment correlation test

The result of this research is that most of students have medium attitude about $66 \%$ toward premarital sexual intercourse, most of students have medium knowledge about $50 \%$ about reproduction health, most of students have enough information from mass media as much as 52\%. There is a relationship between knowledge with the attitude of students about premarital sexual intercourse $(p=0.012)$. There is a significant relationship between mass media and student attitude about premarital sexual relationship $(p=0.008)$

Keywords: knowledge of reproductive health, a role of mass media , attitude

\section{PENDAHULUAN}

Remaja pada saat dahulu dan sekarang sangat berbeda .Pergaulan remaja saat ini telah sampai pada tahap mengkhawatirkan. Semua media massa seringkali menampilkan tayangan yang bisa mengakibatkan rusaknya akhlak generasi penerus bangsa pada saat ini. Data dari BKKBN menyebutkan bahwa angka kehamilan di kalangan remaja di Indonesia cukup tinggi yaitu 48 dari 1000 remaja, dan $58 \%$ remaja putri yang hamil diluar nikah memiliki keinginan untuk melakukan aborsi. Masa remaja dianggap masa rawan oleh kebanyakan orang tua.

Masa remaja yaitu masa dari masa anak beranjak ke usia dewasa. Bermacam macam peristiwa yang bisa terjadi dengan masa ini, oleh karena itu dibutuhkan perhatian, dukungan serta pengawasan dari orang tua, sehingga perilaku remaja bisa lebih terkontrol dan tidak terpengaruh dengan keadaan dunia luar yang bersifat negatif diantaranya peran media massa, lingkungan sekitar dan lain sebagainya. Faktor yang berperan dalam sikap remaja tentang hubungan seksual pranikah ini diantaranya adalah tingkat pengetahuan tentang kesehatan reproduksi dan media massa, sebab itu penulis tertarik untuk melakukan penelitian tentang factor factor yang hubungannya dengan sikap mahasiswa keperawatan tentang hubungan seksual pranikah.

\section{Metode Penelitian}

Metode yang digunakan adalah Observasional dengan menggunakan rancangan penelitian cross sectional. Subjek penelitiannya yaitu mahasiswa keperawatan semester V dan VII di Fakultas IImu Kesehatan Universitas Wiraraja Sumenep sebanyak 128 mahasiswa. Meliputi mahasiswa pria dan wanita. Sebagai sampel penelitian adalah 
mahasiswa keperawatan semester $\mathrm{V}$ dan VII dengan menggunakan rumus slovin yang berjumlah 100. Untuk melihat distribusi frekuensi, dan digunakan uji korelasi Pearson Product Moment untuk melihat apakah ada hubungan yang bermakna.

\section{HASIL PENELTIAN}

\section{a. Tabel Distribusi Frekuensi Sikap}

Tabel 1. Distribusi Frekwensi Sikap Mahasiswa Keperawatan semester V dan VII Terhadap Hubungan Seksual (Intercourse) Pranikah

\begin{tabular}{ccc}
\hline Sikap & F & $\%$ \\
\hline Baik & 15 & $15,00 \%$ \\
Sedang & 66 & $66,00 \%$ \\
Kurang & 19 & $19,00 \%$ \\
\hline Total & 100 & $100,00 \%$
\end{tabular}

Sumber : Data primer 2017

Dari hasil tabel 1 didapatkan hasil bahwa sebagian besar mahasiswa memiliki sikap sedang tentang hubungan seksual pranikah yaitu sebanyak 66 . b. Tabel Distribusi Frekuensi Pengetahuan

Tabel 2. Distribusi Frekwensi Pengetahuan Mahasiswa Keperawatan Semester V da VII Tentang Kesehatan Reproduksi

\begin{tabular}{ccc}
\hline Pengetahuan & $F$ & $\%$ \\
\hline Baik & 23 & 23 \\
Sedang & 50 & 50 \\
Rendah & 27 & 27 \\
\hline Total & 100 & 100
\end{tabular}

Dari tabel 2 sebagian besar mahasiswa memiliki pengetahuan yang sedang tentang kesehatan reproduksi yaitu sebanyak $50 \%$.

\section{c. Data Distribusi Frekuensi Peran Media Massa}

Tabel 3.Distribusi Frekwensi Peran Media Massa bagi Mahasiswa Keperawatan Semester V dan VII

\begin{tabular}{ccc}
\hline Media massa & $\mathrm{f}$ & $\%$ \\
\hline Informasi cukup & 52 & 52.0 \\
Informasi tidak & 48 & 48.0 \\
\hline Total & 100 & 100 \\
\hline
\end{tabular}

Dari tabel 3 sebagian besar mahasiswa memiliki informasi yang cukup dari media massa yaitu sebanyak $52 \%$

\section{d. Hubungan antara Pengetahuan Remaja dengan Sikap mahasiswa Terhadap Hubungan Seksual (Intercourse) Pranikah}

Tabel 4. Tabel Silang antara Variable Pengetahuan Remaja dengan Sikap Terhadap Hubungan Seksual (Intercourse) Pranikah

\begin{tabular}{ccccccccc}
\hline \multirow{2}{*}{ Pengetahuan } & \multicolumn{9}{c}{ Sikap mahasiswa } & \multicolumn{2}{c}{ Total } \\
\cline { 2 - 7 } & \multicolumn{2}{c}{ Kurang } & \multicolumn{2}{c}{ Sedang } & \multicolumn{2}{c}{ Baik } & \multicolumn{2}{c}{} \\
\cline { 2 - 8 } & $\mathrm{N}$ & $\%$ & $\mathrm{n}$ & $\%$ & $\mathrm{n}$ & $\%$ & $\mathrm{~N}$ & $\%$ \\
\hline Rendah & 10 & 45.4 & 10 & 45.4 & 2 & 9.2 & 22 & 100 \\
Sedang & 5 & 8.3 & 40 & 66.7 & 15 & 25 & 60 & 100 \\
Baik & 4 & 22.2 & 12 & 66.6 & 2 & 11.1 & 18 & 100 \\
\hline Total & 19 & 19.0 & 62 & 62.0 & 19 & 19.0 & 100 & 100 \\
\hline
\end{tabular}

Dari tabel 4 didapatkan hasil bahwa signifikasi $0,012(p<0,05, r=0,238)$ artinya mahasiswa yang memiliki yang sedang tentang antara pengetahuan remaja tentang kesehatan kesehatan reproduksi, juga memiliki sikap yang reproduksi dengan sikap mahasiswa sedang tentang seksual pranikah yaitu keperawatan semester V dan VII terhadap sebanyak 66.7\%. Hasil uji statistic hubungan sekaual (intercourse) pranikah ada menunjukkan bahwa pengetahuan remaja hubungan yang signifikan

tentang kesehatan reproduksi pada angka

e. Hubungan Sikap Mahasiswa Terhadap Hubungan Seksual (Intercourse) Pranikah dengan peran media massa

Tabel 5 Tabel Silang antara Sikap Mahasiswa Keperawatan dengan media massa

\begin{tabular}{|c|c|c|c|c|c|c|c|c|}
\hline \multirow{3}{*}{ Peran media massa } & \multicolumn{6}{|c|}{ Sikap mahasiswa } & \multirow{2}{*}{\multicolumn{2}{|c|}{ Total }} \\
\hline & \multicolumn{2}{|c|}{ Kurang } & \multicolumn{2}{|c|}{ Sedang } & \multicolumn{2}{|c|}{ Baik } & & \\
\hline & $\mathrm{n}$ & $\%$ & $\mathrm{n}$ & $\%$ & $\mathrm{n}$ & $\%$ & $\mathrm{n}$ & $\%$ \\
\hline Informasi tidak cukup & 12 & 21.8 & 36 & 65.4 & 7 & 12.8 & 55 & 100 \\
\hline Informasi cukup & 8 & 17.8 & 35 & 77.8 & 2 & 4.4 & 45 & 100 \\
\hline Total & 20 & 20.0 & 71 & 71.9 & 9 & 9.0 & 100 & 100 \\
\hline
\end{tabular}


Dari tabel 5 didapatkan hasil bahwa mahasiswa dengan informasi yang cukup memiliki sikap yang sedang terhadap hubungan seksual pranikah yaitu sebanyak $77.8 \%$

\section{PEMBAHASAN}

\section{Sikap}

Hasil akhir dari sikap tidak dapat langsung dlihat tapi hanya dapat di artikan dari perilaku seseorang yang extrovet. Dalam Notoatmodjo (2003) sikap adalah dampak yang masih belum terlihat dari dalam diri seseorang terhadap suatu rangsangan dari luar. Dari hasil penelitian didapatkan hasil bahwa mahasiswa memiliki sikap sedang sebanyak $66 \%$ tentang seksual pranikah.

\section{Pengetahuan}

Pengetahuan adalah sebuah berita yang digabungkan dengan potensi dan pemahaman untuk melakukan aksi; kemudian terekam di fikiran manusia. Informasi dan data hanya kemampuan untuk memberikan informasi atau bahkan menimbulkan suatu kebingungan, (Meliono,irmayanti, dkk, 2007) Pada dasarnya, pengetahuan tersebut mempunyai suatu kemampuan untuk menganalisa sesuatu hal sebagai hasil dari sesuatu hal Sesuai hasil didapatkan data mahasiswa memiliki pengetahuan sedang sebesar $50 \%$.

\section{Media Massa}

Media massa adalah alat komunikasi mekanis seperti radio,surat kabae, TV yang digunakan untuk menyampaikan pesan ke masyarakat (Cangara,2002)

Sesuai hasil didapatkan data bahwa mahasiswa mendapatkan informasi yang cukup dari media massa tentang pernikahan diluar nikah yaitu sebesar $52 \%$.

\section{Hubungan antara Pengetahuan Remaja dengan Sikap mahasiswa keperawatan semester V dan VII Terhadap Hubungan Seksual (Intercourse) Pranikah}

Sesuai dari pengolahan data didapatkan hasil yaitu pengetahuan remaja yaitu kesehatan reproduksi pada angka signifikasi $0,012(p<0,05, r=0,237)$ artinya terdapat hubungan antara sikap mahasiswa keperawatan semester V dan VII terhadap hubungan seksual (intercourse) pranikah dengan pengetahuan remaja tentang kesehatan reproduksi. Berdasarkan hasil tabulasi silang antara pengetahuan dengan sikap maka didapatkan hasil mahasiswa dengan pengetahuan sedang maka cenderung memiliki sikap yang sedang pula tentang hubungan seksual pranikah yaitu sebanyak $66.7 \%$.

Pengetahuan adalah sebuah berita yang digabungkan dengan potensi dan pemahaman untuk melakukan aksi; kemudian terekam di fikiran manusia. Informasi dan data hanya kemampuan untuk memberikan informasi atau bahkan menimbulkan suatu kebingungan, (Meliono,irmayanti, dkk, 2007) Pada dasarnya, pengetahuan tersebut mempunyai suatu kemampuan untuk menganalisa sesuatu hal sebagai hasil dari sesuatu hal.

Menurut Notoatmodjo (2003) sikap sikap adalah dampak yang masih belum terlihat dari dalam diri seseorang terhadap suatu rangsangan dari luar Pengetahuan yang dimiliki oleh mahasiswa tentunya juga berasal dari beberapa sumber diantaranya kepercayaan, kebiasaan, agama, pengalaman, akal pikiran dan intuisi dari masing masing individu, maka semakin baik pengetahuan yang dimiliki seseorang tentang kesehatan reproduksi,maka akan semakin baik juga sikap yang dimiliki tentang Perilaku seksual pranikah dan sebaliknya. Pengetahuan tentang kesehatan reproduksi dapat diberikan sejak dalam masa pendidikan dini yaitu menengah sehingga dapat menanamkan sikap yang positif tentang bahaya sikap seksual pranikah.

\section{Hubungan antara Peran Media Massa dengan Sikap Mahasiswa Keperawatan Semester V dan VII Terhadap Hubungan Seksual (Intercourse) Pranikah}

Sesuai dari hasil pengolahan data diperoleh angka signifikasi 0,007 ( $p<0,05, r=$ 0,251 ) artinya ada hubungan yang antara sikap mahasiswa keperawatan semester $\mathrm{V}$ dan VII terhadap hubungan sekaual (intercourse) pranikah dengan media massa. Berdasarkan hasil tabulasi silang antara sikaptentang hubungan seksual pranikah dengan media massa maka didapatkan hasil mahasiswa yang mendapatkan informasi yang cukup maka cenderung memiliki sikap yang sedang tentang hubungan seksual pranikah sebanyak $77.8 \%$.

Media massa adalah alat komunikasi mekanis seperti radio,surat kabar, TV yang digunakan untuk menyampaikan pesan ke masyarakat (Cangara, 2002). Menurut Notoatmodjo (2003) sikap adalah sikap adalah 
dampak yang masih belum terlihat dari dalam diri seseorang terhadap suatu rangsangan dari luar Media massa berpengaruh besar dalam mempengaruhi terbentuknya sikap mahasiswa tentang hubungan seksual pranikah. Informasi tentang kesehatan reproduksi dan bahaya seksual pranikah bisa di sampaikan melalui media elektronik, radio, lefleat, radio dan media lainnya yang ada di masyarakat.

\section{KESIMPULAN DAN SARAN}

A. Kesimpulan

1. Mahasiswa memiliki sikap sedang tentang hubungan seksual pranikah sebanyak $66 \%$

2. Mahasiswa memiliki pengetahuan sedang tentang kesehatan reproduksi sebanyak $50 \%$

3. Mahasiswa memiliki informasi yang cukup dari media massa sebanyak $52 \%$

4. Ada suatu hubungan yang signifikan antara sikap mahasiswa tentang hubungan seksual pranikah $(p=0.012)$ dengan pengetahuan tentang kesehatan reproduksi

5. Ada suatu hubungan yang signifikan antara sikap dengan media massa

B. Saran-saran

1. Bagi Dinas Kesehatan

Dinas kesehatan melalui puskesmas bisa memberikan penyuluhan atau konseling tentang kesehatan reproduksi ke setiap institusi pendidikan

2. Bagi Institusi Pendidikan

Memberikan informasi tentang faktor

faktor apa saja yang mempengaruhi sexual intercourse.

3. Bagi Dinas Pendidikan

Dinas pendidikan bisa memberikan pendidikan tentang kesehatan reproduksi pada remaja sejak pendidikan dini.

\section{DAFTAR PUSTAKA}

Asrori M. Psikologi Remaja. PT. Bumi Aksara, Jakarta, 2005.

Ari Kunto.Manajemen Penelitian. PT. Reneka Cipta, Jakarta, 2000.

Ary GA, Rahasia Sukses Membangun Kecerdasan Emosi dan Spiritual, Penerbit Arga, Bandung, 1997.

Azwar, S. Sikap Manusia Teori dan Pengukurannya. (Edisi 2) Cetakan VI. Pustaka Pelajar, Yoyakarta, 1995.

Departemen Kesehatan, RI. Pelayanan Peduli Kesehatan Reproduksi Remaja. Makalah Pelatihan Nasional Kesehatan Peduli Remaja. Dirjen Kesehatan Keluarga, Jakarta, 2003.
Efendy, A. Prilaku Sehat, Kebiasaan Merokok dan Minuman Keras di Kalangan Remaja Bali. PT. Reneka Cipta, Jakarta, 2000.

Erwinalia.blogspot.co.id/2013/10/makalahpergavian-remaja-masakini.html 